\title{
Estimation of Leaf Water Use Efficiency Threshold Values for Water Stress in Winter Wheat (Triticum aestivum L.)
}

\author{
Qiu Xinqiang, Zhang Yushun, Qin Haixia, Wang Min, Wang Yanping, Yang Haochen, \\ and Lu Zhenguang
}

Henan Provincial Water Conservancy Research Institute/Center of Efficient Irrigation Engineering and Technology Research of Henan Province, Zhengzhou 450003, China

Correspondence should be addressed to Lu Zhenguang; skslzg@hnsl.gov.cn

Received 18 September 2020; Revised 3 November 2020; Accepted 8 December 2020; Published 31 December 2020

Academic Editor: Yuan Li

Copyright (C) 2020 Qiu Xinqiang et al. This is an open access article distributed under the Creative Commons Attribution License, which permits unrestricted use, distribution, and reproduction in any medium, provided the original work is properly cited.

\begin{abstract}
Drought significantly threatens crop productivity and food security worldwide. However, the severity of drought is predicted to increasingly intensify in the future. To provide an antidrought strategy for farmers and breeders, the response of stomatal behavior of crops to water stress should be well studied. In this study, a lysimeter experiment was conducted to study the relationship between gas exchange parameters and grain yields of winter wheat. Light, moderate, and severe drought levels were imposed at seedling, jointing, heading, and filling stages. The results showed that crop evapotranspiration $\left(\mathrm{ET}_{c}, \mathrm{~mm}\right)$ of winter wheat during the entire growing season was limited by drought imposed at any growth stage, and $\mathrm{ET}_{\mathrm{c}}$ under severe drought treatment was always the lowest. The stomatal limitation value had a significant linear correlation with the stomatal conductance $\left(\mathrm{Gs}, \mu \mathrm{mol} \mathrm{mol} \mathrm{H} \mathrm{O} \mathrm{m}^{-2} \mathrm{~s}^{-1}\right.$ ) and transpiration rate $\left(\mathrm{Tr}, \mathrm{mmol} \mathrm{H}_{2} \mathrm{O} \mathrm{m}^{-2} \mathrm{~s}^{-1}\right)$. Light and moderate drought levels at the seedling stage did not generate irreversible physiological stress on wheat plants, while severe drought at any growth stage caused significant reduction in gas exchange parameters and grain yields. Theoretical threshold values of leaf water use efficiency $\left(\mathrm{WUE}_{1}\right)$ for light, moderate, and severe drought levels were $2.62,3.36$, and $4.11 \mu \mathrm{mol} \mathrm{mmol}^{-1}$, respectively. The threshold values are useful to provide theoretical reference for achieving smart irrigation in the North China Plain.
\end{abstract}

\section{Introduction}

Drought is one of the most common factors threatening food security worldwide. It is predicted that the severity of drought will continue in the future under the current climate change scenarios [1]. Nevertheless, global demand for major grains such as wheat and maize is projected to increase by $70 \%$ by 2050 due to the ever-increasing population [2]. This means the agricultural sector will double the present consumption of the water resources on the planet under the current water use efficiency (WUE) level [3]. To mitigate the conflict between water consumption for food production and water supply for agriculture, modern irrigation technology should be developed toward smart and precision irrigation with efficient use of water [4]. However, the present efficiency of irrigation in the world is relatively low, especially in Southeast Asia, North Africa, and South America [5-7]. Taking China, for example, the mean utilization coefficient of irrigation water was 0.45 in 2019 [8]. Precision irrigation according to the crop water requirement is the key to achieving high leaf water use efficiency $\left(\mathrm{WUE}_{1}\right)$. However, the main difficulty for precision irrigation lies in real-time and rapid monitoring of gas exchange parameters of crop leaves, such as the stomatal conductance (Gs, $\mu \mathrm{mol} \mathrm{mol} \mathrm{H}_{2} \mathrm{O} \mathrm{m}^{-2} \mathrm{~s}^{-1}$ ) and transpiration rate $\left(\mathrm{Tr}, \mathrm{mmol} \mathrm{H}_{2} \mathrm{O} \mathrm{m}^{-2} \mathrm{~s}^{-1}\right)$, and $\mathrm{WUE}_{1}$ [9].

The North China Plain (NCP) is one of the most important granaries in China, accounting for 30 and $60 \%$ of the domestic maize (Zea mays L.) and wheat (Triticum aestivum L.) production [10]. Over recent years, NCP has been subjected to serious water shortages due to the rapid development of irrigated agriculture. For example, groundwater for irrigated agriculture in the NCP has accounted for nearly $70 \%$ of total water use in 2015 [11]. Consequently, every year's decline of the groundwater table reached $1.0 \mathrm{~m}$ over 
the past decade, causing the deepest groundwater table of $105 \mathrm{~m}$ in the groundwater depression cone [12]. During winter wheat growing seasons, only $25-40 \%$ of the crop water requirement can be met by seasonal precipitation, which is around $100-180 \mathrm{~mm}$ in the NCP [3]. Generally, the crop needs 2-4 times of irrigation to meet the water requirement and achieve high yield formation of wheat. Therefore, timely irrigation according to the water requirement of crops is the key to high productivity of winter wheat. However, the main difficulty for timely irrigation remains in real-time and rapid monitoring of crop water status. Some scholars developed a probabilistic method for modeling the dynamics of soil water content to guide irrigation, but the model is too complicated to be of wide practical use [13-15]. Using a crop canopy temperature monitoring system which measured real-time data at a $1 \mathrm{~h}$ interval, Jiabing et al. [16] adopted the difference between canopy temperature and air temperature to identify the crop water deficit, which could be further used to trigger irrigation. However, how to reasonably separate canopy temperature from surface temperature when the vegetation coverage is low caused overestimation of crop transpiration [17]. Moreover, how to accurately determine dependable threshold values for irrigation decision-making is also a difficult point for automatic irrigation [18]. So far, few publications have been found using $\mathrm{WUE}_{1}$ as the threshold value of wheat to support data-driven automatic irrigation. In practice, less is known about how to quantitatively analyze the soil moisture status through monitoring crop water status and other photosynthetic parameters, which is critical to determine the irrigation timing and amount.

Accurate identification and measurement of crop water status is the basis for smart irrigation [19]. In order to make crops grow normally without water stress, timely irrigation should be conducted before excessive drought occurs. Studies have shown that, when subjected to drought stress, crop leaves always make the first and rapid response to water stress [20]. Besides, the leaf is a major carrier where photosynthesis and crop transpiration occur. Crops regulate the transpiration rate through adjusting stomatal conductance so that they can maintain the balance of plant water status and intercellular $\mathrm{CO}_{2}$ concentration [21] and cool down themselves when exposed to high temperature [22]. Also, leaf water potential is one of the most important indicators that is associated with stomatal conductance [23], and it will change immediately after the change of stomatal conductance [24]. Leaf water use efficiency $\left(\mathrm{WUE}_{\mathrm{l}}\right)$ is defined as the ratio of photosynthesis to transpiration, which reflects the change of related quantity in the process of leaf gas exchanges [25]. Moreover, intercellular $\mathrm{CO}_{2}$ concentration (Ci) is an important decision basis to determine whether the main reason for the change of the photosynthetic rate is attributable to stomatal factors [26]. Under soil water stress, there is a "threshold" response of photosynthesis of wheat leaves to soil water content [27]. When the intercellular $\mathrm{CO}_{2}$ concentration of leaves changes from decreasing to increasing, it indicates that the main reason for the decrease of the photosynthetic rate is caused by water stress changes from stomatal limitation to nonstomatal limitation [28, 29]. It is known that the moderate water deficit in a specific growth period does not reduce crop yield but increases crop productivity and WUE $[30,31]$.

We hypothesize that timely and appropriate irrigation can be achieved based on the real-time crop water requirement by monitoring gas exchange parameters such as $\mathrm{WUE}_{\mathrm{l}}$ as threshold values of crops. The objectives of this study are as follows: (i) to compare the difference of gas exchange parameters of winter wheat leaves under different water stress conditions in a lysimeter experiment, (ii) to clarify the response of leaf stomatal behavior to water stress, and (iii) to figure out the threshold values of $\mathrm{WUE}_{\mathrm{l}}$, providing guidance for water-saving and smart irrigation of winter wheat in the NCP.

\section{Materials and Methods}

2.1. Site Description. The experiment was carried out at the Maozhuang Experimental Station of Henan Water-Saving Irrigation Engineering Technology Research Center, Central Station of Henan Irrigation Experiment, China $\left(34^{\circ} 16^{\prime} \mathrm{N}\right.$, $112^{\circ} 42^{\prime}$ E, a.s.l. $85 \mathrm{~m}$ ) (see Figure 1). The place has a continent temperate monsoon climate. The mean annual temperature is $14.0-14.3^{\circ} \mathrm{C}$, mean annual precipitation is $640.9 \mathrm{~mm}$, frost-free period is $220 \mathrm{~d}$, and annual sunshine hours are about $2400 \mathrm{~h}$. The soil was a silty loam soil. The field water holding capacity in $0-100 \mathrm{~cm}$ soil layers is $23 \%$ (by weight), average bulk density in the same layers is $1.42 \mathrm{~g} \mathrm{~cm}^{-3}$, and water table was detected more than $5 \mathrm{~m}$ below the soil surface. The content of organic matter, total phosphorus, total potassium, total nitrogen, alkali hydrolyzable nitrogen, available phosphorus, and potassium in $0-30 \mathrm{~cm}$ soil layers was $5.62 \mathrm{~g} \mathrm{~kg}^{-1}, 0.44 \mathrm{~g} \mathrm{~kg}^{-1}, 15.12 \mathrm{~g} \mathrm{~kg}^{-1}, 0.37 \mathrm{~g} \mathrm{~kg}^{-1}, 24.91 \mathrm{mg} \mathrm{kg}^{-1}$, $23.89 \mathrm{mg} \mathrm{kg}^{-1}$, and $75 \mathrm{mg} \mathrm{kg}^{-1}$, respectively.

2.2. Experimental Design. The field experiments were carried out in a lysimeter facility equipped with an automatic rainproof shelter. The research facility consisted of 24 lysimeters (3.3 mlong $\times 2.0 \mathrm{~m}$ wide $\times 2.0 \mathrm{~m}$ deep) packed uniformly with silty loam soil. These lysimeters were arranged in two rows, and between the rows of each system, a $2.5 \mathrm{~m}$ wide concrete platform was constructed level with the top of the lysimeters. The electrically operated double rain shelters were installed for the lysimeters. The rainproof shelters were moved over all lysimeters before precipitation happened.

Popularly used wheat seeds (c.v. Zhoumai 22) were selected as the experimental materials. Nine rows were sown in each lysimeter with a row spacing of $20 \mathrm{~cm}$ and a sowing rate of $150 \mathrm{~kg} \mathrm{~h} \mathrm{~m}^{-2}$. The experiment was conducted in two wheat growing seasons (2012-2013 and 2013-2014). Wheat was sown on October 17, 2012, and October 12, 2013, and harvested on May 30, 2013, and 2014. The whole growth period was $225 \mathrm{~d}$ and $230 \mathrm{~d}$, respectively. Before sowing, the soil was deeply ploughed. While ploughed, compound fertilizer (15-15-15 of N- $\mathrm{P}_{2} \mathrm{O}_{5}-\mathrm{K}_{2} \mathrm{O}$, Shandong Kingenta Ecological Engineering Group Company, LY, China) was applied at the rate of $750 \mathrm{~kg} \mathrm{ha}^{-1}$. In the meantime, $10 \mathrm{tha}^{-1}$ of dry chicken manure was applied as amendment fertilizer. After sowing, full irrigation of $65 \mathrm{~mm}$ was applied to guarantee seed germination. Each plot was irrigated independently, 

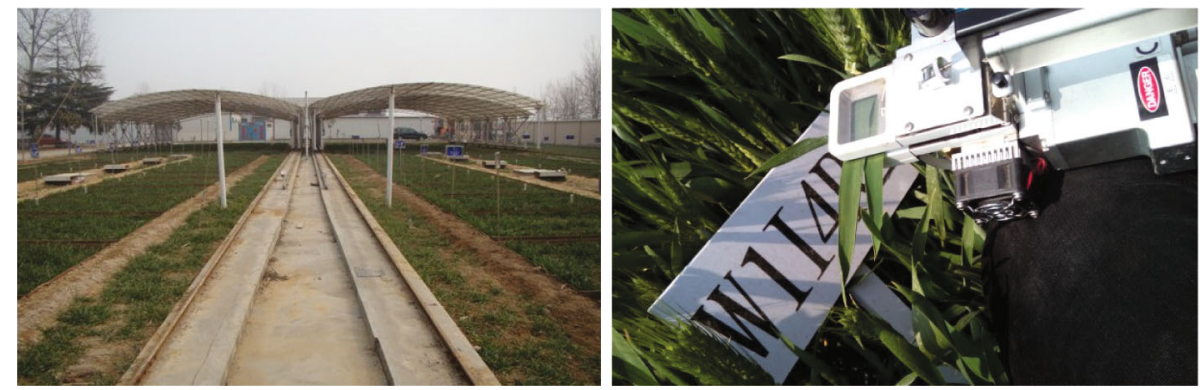

Figure 1: Photos of the field experiments.

and the type of irrigation was surface irrigation. To measure and control irrigation amount, a precision flow meter (Shanghai Water Meter Manufacturing Ltd., Co., Shanghai, China) was adopted. Weed and pest control was applied according to local governmental recommendations. The field crop management was kept the same during the two growing seasons of winter wheat.

In this experiment, 3 drought levels expressed in percentage of field holding capacity (\%FC) were arranged, including the light drought level $(55 \% \mathrm{FC})$, moderate drought level $(45 \% \mathrm{FC})$, and severe drought level $(35 \% \mathrm{FC})$, respectively. Irrigation was ceased once relative soil moisture content (\%FC) reached the 3 corresponding drought levels for each treatment. Furthermore, the 3 drought levels were separately imposed at the seedling stage, jointing stage, heading stage, and filling stage, respectively. Furthermore, to investigate the effects of continuous drought on crop growth, the moderate drought level $(45 \% \mathrm{FC})$ was continuously imposed in the early growth period (i.e., seedling+jointing stages), middle growth period (jointing+heading stages), and late growth period (heading+filling stages), respectively, whereas the suitable soil moisture level, whose relative soil water content was kept $\geq 65 \% \mathrm{FC}$ in the whole growth period, was taken as control (CK). Consequently, a total of 18 irrigation treatments were set up (see Figure 2).

\subsection{Data Collection and Measurements}

2.3.1. Soil Water Content. Soil water content (\%) was measured at $20 \mathrm{~cm}$ increments to a depth of $100 \mathrm{~cm}$ using the soil core method. Soil samples were taken every $7 \mathrm{~d}$ and were oven-dried at $105^{\circ} \mathrm{C}$ for $24 \mathrm{~h}$ for analysis of the gravimetric soil water content. Additional measurement was conducted before and after irrigation.

2.3.2. Grain Yield. At maturity, 9 middle rows in $3.3 \mathrm{~m}$ long were selected from each plot to determine grain yield. All the plants in each plot were hand-harvested and air-dried for 2 weeks until constant mass, and then the grain was separated, cleaned, and weighed. Grain yield was calculated on a dry matter basis (13\%). Besides, ten representative winter wheat plants were randomly selected for the investigation of yield components.

2.3.3. Leaf Gas Exchange Parameters. Relevant leaf gas exchange parameters, including the photosynthetic rate $\left(\mathrm{Pn}, \mu \mathrm{mol} \mathrm{CO} \mathrm{m}^{-2} \mathrm{~s}^{-1}\right)$, transpiration rate $(\mathrm{Tr}, \mathrm{mmol}-$ $\left.\mathrm{H}_{2} \mathrm{O} \mathrm{m}^{-2} \mathrm{~s}^{-1}\right)$, stomatal conductance $\left(\mathrm{Gs}, \mathrm{mol} \mathrm{H}_{2} \mathrm{O} \mathrm{m}^{-2} \mathrm{~s}^{-1}\right.$ ), and intercellular $\mathrm{CO}_{2}$ concentration $\left(\mathrm{Ci}, \mu \mathrm{mol} \mathrm{CO} \mathrm{mol}^{-1}\right.$ air), were measured from 9:30 to $12: 30$ a.m. at each major growth stage on the top full leaves before flag leaves appeared and on the flag leaves after their appearance. Three uniform plants from three selected sampling areas in each plot were measured using a Li-6400XT Portable Photosynthesis System (Li-Cor Inc., Lincoln, NE, USA). The chamber was adjusted to $25^{\circ} \mathrm{C}$ (temperature), ambient $\mathrm{CO}_{2}$ concentration $(\mathrm{Ca})$ was $360 \mu \mathrm{M} \mathrm{mol}^{-1}$, and photosynthetic photon flux density is $800 \mu \mathrm{M} \mathrm{m}^{-2} \mathrm{~s}^{-1}$. Leaf water use efficiency $\left(\mathrm{WUE}_{\mathrm{l}}=\mathrm{Pn} / \mathrm{Tr}\right.$, $\mu \mathrm{mol} \mathrm{mmol}^{-1}$ ) and stomatal limitation ( $\left.\mathrm{Ls}=1-\mathrm{Ci} / \mathrm{Ca}\right)$ were calculated accordingly.

2.4. Statistical Analysis. All data were subjected to analysis of variance (ANOVA) using SPSS version 24.0 (IBM Corp., Armonk, NY), and differences between the means were tested by the least significant difference (Duncan's multiple comparison method). Significance was declared at the probability level of 0.05 unless otherwise stated. All figures were illustrated using Origin 9.0 software (OriginLab, Northampton, USA). Relationships between $\mathrm{WUE}_{\mathrm{l}}$, Ls, and gas exchange parameters were estimated by means of regression using the Levenberg-Marquardt algorithm.

\section{Results and Discussion}

3.1. Effects of Water Stress at the Seedling Stage on Leaf Gas Exchange of Winter Wheat. In this experiment, leaf gas exchange parameters, including $\mathrm{Pn}, \mathrm{Tr}, \mathrm{Ci}$, and Gs, were measured at the seedling stage during the two growing seasons (see Figure 3). Pn, Tr, Ci, and Gs of winter wheat leaves during the drought period (March 22-27) decreased continuously with the intensification of drought levels. T4 treatment showed the greatest effects on suppressing gas exchange parameters. In detail, T4 decreased Pn by $35.4 \%$, $\operatorname{Tr}$ by $55.0 \%$, Ci by $16.5 \%$, and Gs by $43.6 \%$, respectively, compared with CK (T1). The difference was also significant between T2 and T4. After rewatering at the jointing stage, gas exchange parameters of each drought treatment increased. Crop growth performance of T2 and T3 treatments was generally better than that of CK. What is more, the growth performance of T4 treatment was only slightly weaker than that of CK. Therefore, although drought at the seedling stage weakened the gas exchange process of winter wheat leaves to a certain extent, it had nonsignificant adverse effects on photosynthetic rates after rewatering at the jointing stage. Previous studies have shown that moderate water 


\begin{tabular}{|c|c|c|c|c|}
\hline Growth stages & Seedling & Jointing & Heading & Filling \\
\hline T1 (CK) & Non-stress $(65 \% \mathrm{FC})$ & Non-stress $(65 \% \mathrm{FC})$ & Non-stress $(65 \% \mathrm{FC})$ & Non-stress $(65 \% \mathrm{FC})$ \\
\hline $\mathrm{T} 2$ & Light drought ( $55 \% \mathrm{FC}$ ) & Non-stress $(65 \% \mathrm{FC})$ & Non-stress $(65 \% \mathrm{FC})$ & Non-stress $(65 \% \mathrm{FC})$ \\
\hline $\mathrm{T} 3$ & Moderate drought $(45 \% \mathrm{FC})$ & Non-stress $(65 \% \mathrm{FC})$ & Non-stress $(65 \% \mathrm{FC})$ & Non-stress $(65 \% \mathrm{FC})$ \\
\hline $\mathrm{T} 4$ & Sever drought $(35 \% \mathrm{FC})$ & Non-stress $(65 \% \mathrm{FC})$ & Non-stress $(65 \% \mathrm{FC})$ & Non-stress $(65 \% \mathrm{FC})$ \\
\hline T5 & Non-stress $(65 \% \mathrm{FC})$ & Light drought $(55 \% \mathrm{FC})$ & Non-stress $(65 \% \mathrm{FC})$ & Non-stress $(65 \% \mathrm{FC})$ \\
\hline T6 & Non-stress $(65 \% \mathrm{FC})$ & Moderate drought ( $45 \% \mathrm{FC})$ & Non-stress $(65 \% \mathrm{FC})$ & Non-stress $(65 \% \mathrm{FC})$ \\
\hline T7 & Non-stress $(65 \% \mathrm{FC})$ & Sever drought $(35 \% \mathrm{FC})$ & Non-stress $(65 \% \mathrm{FC})$ & Non-stress $(65 \% \mathrm{FC})$ \\
\hline T8 & Non-stress $(65 \% \mathrm{FC})$ & Non-stress $(65 \% \mathrm{FC})$ & Light drought $(55 \% \mathrm{FC})$ & Non-stress $(65 \% \mathrm{FC})$ \\
\hline T9 & Non-stress $(65 \% \mathrm{FC})$ & Non-stress $(65 \% \mathrm{FC})$ & Moderate drought $(45 \% \mathrm{FC})$ & Non-stress $(65 \% \mathrm{FC})$ \\
\hline T10 & Non-stress $(65 \% \mathrm{FC})$ & Non-stress $(65 \% \mathrm{FC})$ & Sever drought (35\%FC) & Non-stress $(65 \% \mathrm{FC})$ \\
\hline T11 & Non-stress $(65 \% \mathrm{FC})$ & Non-stress $(65 \% \mathrm{FC})$ & Non-stress $(65 \% \mathrm{FC})$ & Light drought (55\%FC) \\
\hline T12 & Non-stress $(65 \% \mathrm{FC})$ & Non-stress $(65 \% \mathrm{FC})$ & Non-stress $(65 \% \mathrm{FC})$ & Moderate drought $(45 \% \mathrm{FC})$ \\
\hline $\mathrm{T} 13$ & Non-stress $(65 \% \mathrm{FC})$ & Non-stress $(65 \% \mathrm{FC})$ & Non-stress $(65 \% \mathrm{FC})$ & Sever drought (35\%FC) \\
\hline T14 & Moderate drought $(45 \% \mathrm{FC})$ & Moderate drought ( $45 \% \mathrm{FC})$ & Non-stress $(65 \% \mathrm{FC})$ & Non-stress $(65 \% \mathrm{FC})$ \\
\hline T15 & Non-stress $(65 \% \mathrm{FC})$ & Moderate drought $(45 \% \mathrm{FC})$ & Moderate drought ( $45 \% \mathrm{FC})$ & Non-stress $(65 \% \mathrm{FC})$ \\
\hline T16 & Non-stress $(65 \% \mathrm{FC})$ & Non-stress $(65 \% \mathrm{FC})$ & Moderate drought $(45 \% \mathrm{FC})$ & Moderate drought $(45 \% \mathrm{FC})$ \\
\hline
\end{tabular}

FIGURE 2: Diagram of the nonstress (T1, CK), the three drought stress levels (light, moderate, and severe) separately imposed at seedling (T2, $\mathrm{T} 3$, and T4), jointing (T5, T6, and T7), heading (T8, T9, and T10), and filling (T11, T12, and T13) stages, and the moderate drought stress continuously imposed at seedling and jointing stages (T14), jointing and heading stages (T15), and heading and filling stages (T16), respectively. FC: field holding capacity $\left(\mathrm{cm}^{3} \mathrm{~cm}^{-3}\right) . \% \mathrm{FC}$ in the table represents the lower limit for triggering irrigation.

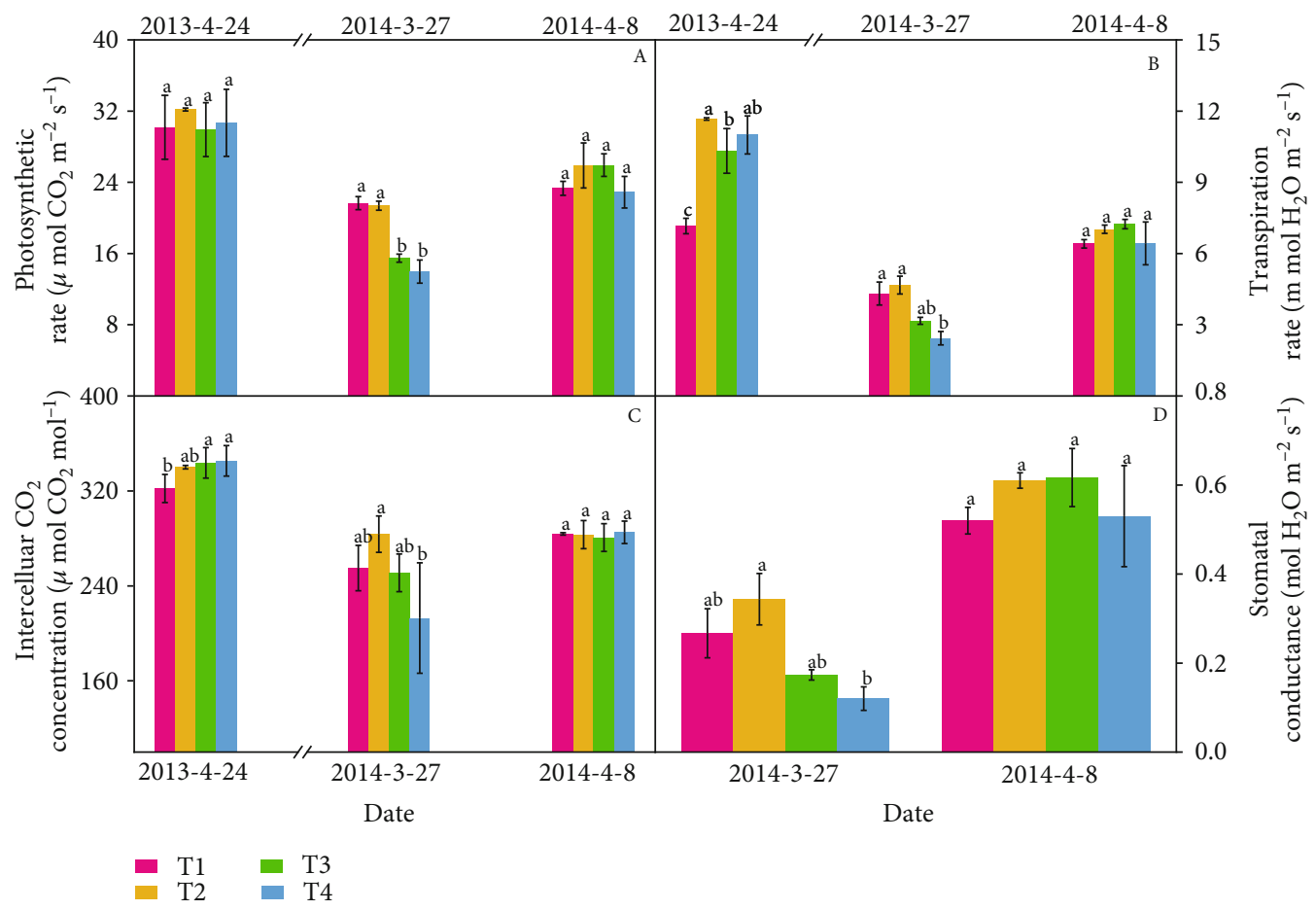

FIGURE 3: Variations in leaf gas exchange parameters of winter wheat under well-watered control treatment (T1), light drought (T2), moderate drought (T3), and severe drought (T4) stress at the seedling stage. Data are the means \pm standard errors (SE) of three replicates, where $n=3$ for the photosynthetic rate $(\mathrm{Pn})$, transpiration rate ( $\mathrm{Tr})$, intercellular $\mathrm{CO}_{2}$ concentration $(\mathrm{Ci})$, and stomatal conductance (Gs). Different letters above the bars indicate statistical significance $(p \leq 0.05)$. 


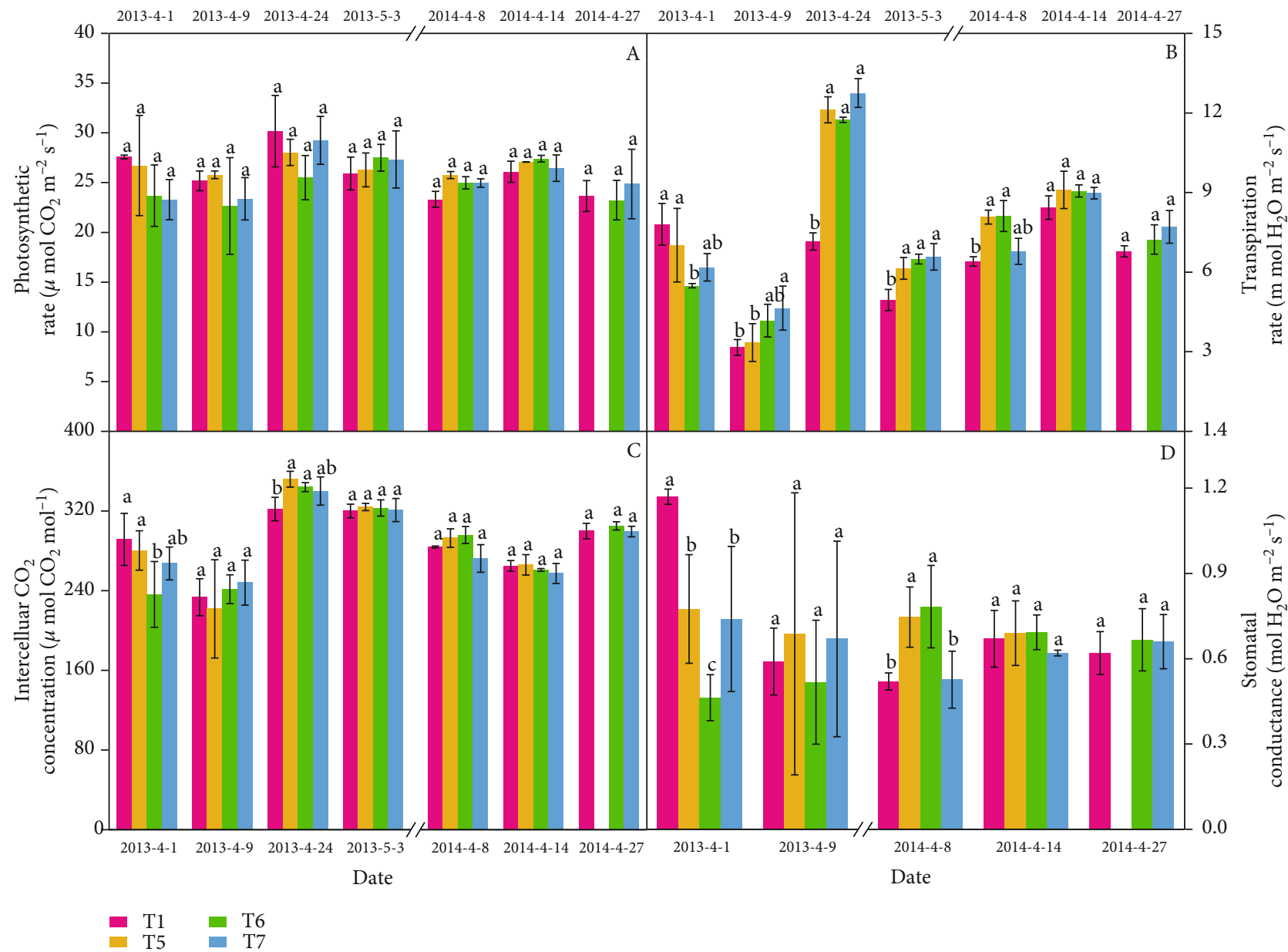

FIgURE 4: Variations in leaf gas exchange parameters of winter wheat under well-watered control treatment (T1), light drought (T5), moderate drought (T6), and severe drought (T7) stress at the jointing stage. Data are the means \pm standard errors (SE) of three replicates, where $n=3$ for the photosynthetic rate $(\mathrm{Pn})$, transpiration rate $(\mathrm{Tr})$, intercellular $\mathrm{CO}_{2}$ concentration $(\mathrm{Ci})$, and stomatal conductance $(\mathrm{Gs})$. Different letters above the bars indicate statistical significance $(p \leq 0.05)$.

stress in the early stage could ensure a higher photosynthetic rate of wheat leaves and helped to improve WUE, while the severe water deficit had a significant negative effect on the stomatal opening [32, 33]. Also, grain yield of light and moderate drought treatments at the seedling stage was not significantly affected, which was consistent with the results of previous studies [34,35]. Consequently, properly intensifying soil water stress at the seedling stage of winter wheat not only is conducive to water saving but also can achieve the purpose of "promoting root penetration" in the early growth stage.

3.2. Effects of Water Stress at the Jointing Stage on Leaf Gas Exchange of Winter Wheat. Pn, Tr, and Ci of winter wheat leaves decreased at first and then increased from jointing to flowering (see Figure 4). At the jointing stage of the 20122013 growing season, Pn of drought treatments was generally lower than that of CK. The maximum reduction in Pn was 7.1\% (light drought), 15.5\% (moderate drought), and 15.6\% (severe drought), respectively, compared with CK. The difference in Pn between drought treatments and CK in the 20132014 growing season was relatively small. Compared with
$\mathrm{CK}, \mathrm{Ci}, \mathrm{Tr}$, and $\mathrm{Gs}$ decreased by $10.4 \%, 20.2 \%$, and $43.6 \%$, respectively, for light, moderate, and severe treatments, before irrigation (April 1, 2014). After irrigation, the above indexes returned to normal levels rapidly (April 9, 2014), and $\mathrm{Tr}$ values increased by $16.5 \%$ (T5), $31.9 \%$ (T6), and $46.7 \%$ (T7), respectively, showing a rapid stomatal response to soil moisture restoration. Therefore, we pointed out that appropriate drought stress at the jointing stage helped promote crop root growth and improve water uptake. Our study demonstrated that physiological indexes (e.g., Pn, Tr, and Ci) of winter wheat (c.v. Zhoumai 24) were rapidly compensated after light water stress rewatering, and the supercompensation effect was observed after moderate water stress rewatering at the jointing stage. Similar results were also observed in another lysimeter experiment using another winter wheat variety (c.v. Shijiazhuang 8) as experimental material [36].

3.3. Effects of Water Stress at the Heading Stage on Leaf Gas Exchange of Winter Wheat. There were significant differences between treatments T8 and T10 (see Figure 5). During the 2013-2014 growing season, Pn of T10 treatment decreased by $14.3 \%$ compared with CK. Under treatments 


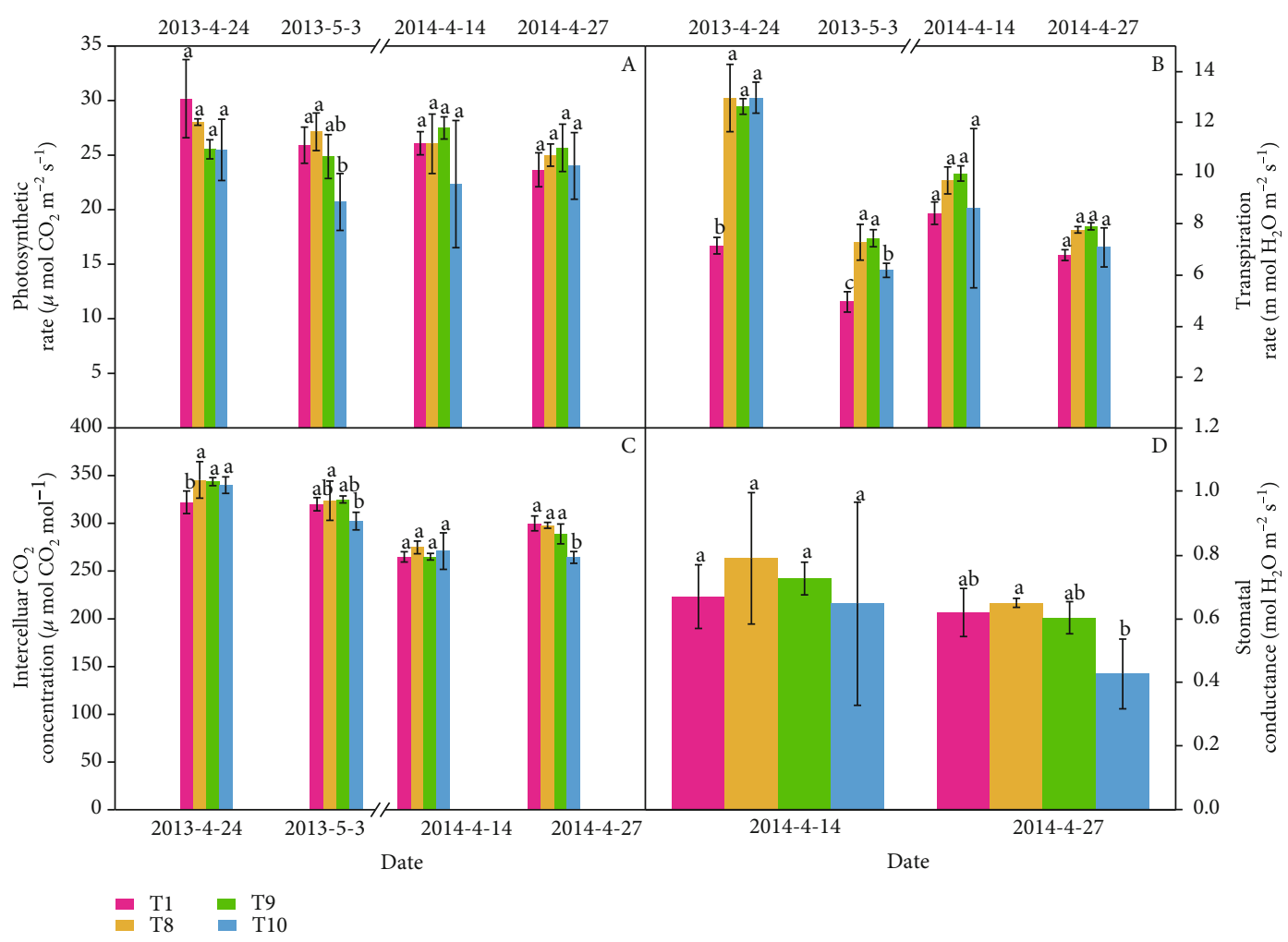

FIGURE 5: Variations in leaf gas exchange parameters of winter wheat under well-watered control treatment (T1), light drought (T8), moderate drought (T9), and severe drought (T10) stress at the heading stage. Data are the means \pm standard errors (SE) of three replicates, where $n=3$ for the photosynthetic rate $(\mathrm{Pn})$, transpiration rate $(\mathrm{Tr})$, intercellular $\mathrm{CO}_{2}$ concentration $(\mathrm{Ci})$, and stomatal conductance $(\mathrm{Gs})$. Different letters above the bars indicate statistical significance $(p \leq 0.05)$.

T8 and T9, gas exchange parameters did not significantly decrease, while $\mathrm{Tr}$ was increased by $15.3 \%$ and $18.5 \%$, respectively, compared with CK. Under continuous water stress, Pn, Tr, and Gs of all treatments decreased, while Ci increased (except for that of severe drought treatment). The results showed that Pn and Tr of T10 treatment were significantly lower than those of other drought treatments. Furthermore, compared with $\mathrm{CK}, \mathrm{Ci}$ and Gs of T10 treatment were significantly decreased by $11.9 \%$ and $31.2 \%$, respectively. Severe drought at the heading stage had significant negative effects on gas exchange parameters of winter wheat leaves, and the variability of the above parameters was large.

3.4. Effects of Water Stress at the Filling Stage on Leaf Gas Exchange of Winter Wheat. With the intensification of water stress, Pn, Tr, and Gs of drought treatments decreased significantly at the filling stage (see Figure 6). Pn, Tr, Ci, and Gs of T13 treatment decreased by $74.9 \%, 73.2 \%, 7.64 \%$, and $87.1 \%$, respectively, compared with $\mathrm{CK}$ at the filling stage. However, $\mathrm{Pn}, \mathrm{Tr}, \mathrm{Ci}$, and Gs of T11 and T12 treatments did not significantly decrease. Under continuous water stress, Pn, Tr, Ci, and $\mathrm{Gs}$ of each drought treatment decreased significantly by 40.6\% (Pn), 47.7\% (Tr), 11.1\% (Ci), and 69.6\% (Gs), respectively. Severe drought had the greatest decreasing effect on $\mathrm{Pn}, \mathrm{Tr}$, and Gs at the filling stage.

3.5. Effects of Continuous Water Stress on Leaf Gas Exchange of Winter Wheat. During the drought period of the 2012-
2013 growing season, $\mathrm{Tr}, \mathrm{Ci}$, and $\mathrm{Gs}$ of continuous drought treatments in the early growth stage decreased by $19.6 \%$, $17.3 \%$, and $50.4 \%$, respectively (see Figure 7). Similarly, those of continuous drought treatments in the late growth stage decreased by $45.2 \%(\mathrm{Tr}), 15.7 \%(\mathrm{Ci})$, and $78.9 \%(\mathrm{Gs})$, respectively. After rewatering, differences of $\mathrm{Tr}, \mathrm{Ci}$, and $\mathrm{Gs}$ between the drought treatments and CK were significantly reduced. $\mathrm{Ci}$ and Gs returned to the level of CK treatment, whereas $\mathrm{Tr}$ "rebounded" to 1.92 times (2012-2013) and 1.28 times (2013-2014) the CK treatment. The differences between continuous drought treatments and CK began to be significant at the filling stage, and they gradually increased with time and reached the maximum in the late filling stage.

3.6. Correlations of Leaf Water Use Efficiency and Stomatal Limitation Values Related to Leaf Gas Exchange Parameters. Stomatal limitation (Ls) was defined as $1-\mathrm{Ci} / \mathrm{Ca}$. Ls had a quadratic relationship with $\mathrm{Pn}$ and a linear relationship with Gs and $\operatorname{Tr}$ (see Figure 8). Ls mainly concentrated at the level below 0.3 . Leaf water use efficiency $\left(\mathrm{WUE}_{1}\right)$ had a quadratic relationship with $\mathrm{Pn}$ and $\mathrm{Tr}$ and a nonlinear ellipse relationship with Gs. Furthermore, $\operatorname{Tr}$ decreased under drought stress, and the decreasing rates of $\mathrm{Tr}$ became larger with the intensification of water stress. Our study showed that moderate water stress led to the increase of $\mathrm{WUE}_{1}$, and $\mathrm{WUE}_{1}$ continued to increase even if wheat crops suffered severe drought stress. Under soil water stress, the plant stomatal regulation mechanism is considered to be feedback to make plants 


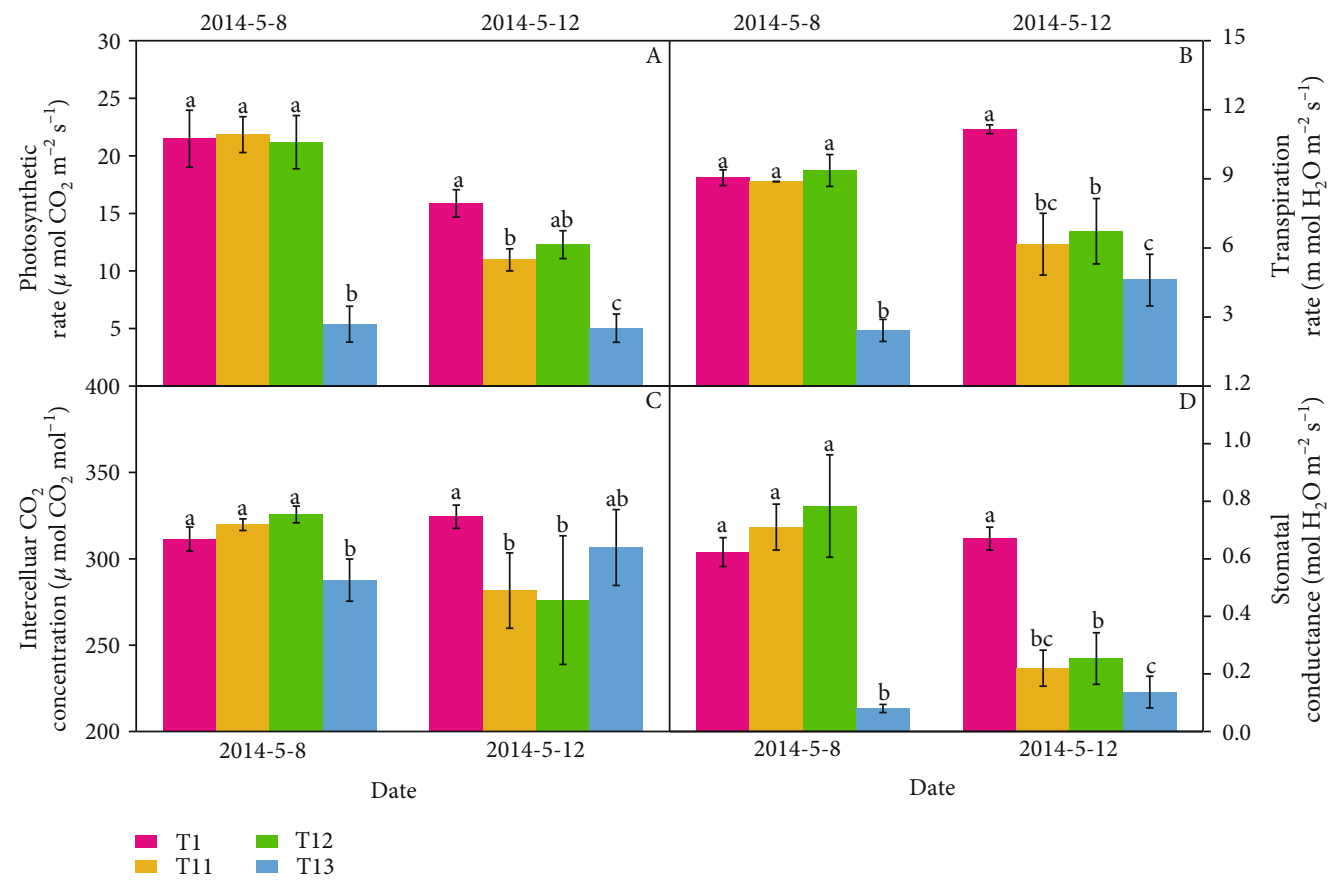

FIGURE 6: Variations in leaf gas exchange parameters of winter wheat under well-watered control treatment (T1), light drought (T11), moderate drought (T12), and severe drought (T13) stress at the filling stage. Data are the means \pm standard errors (SE) of three replicates, where $n=3$ for the photosynthetic rate $(\mathrm{Pn})$, transpiration rate $(\mathrm{Tr})$, intercellular $\mathrm{CO}_{2}$ concentration $(\mathrm{Ci})$, and stomatal conductance (Gs). Different letters above the bars indicate statistical significance $(p \leq 0.05)$.

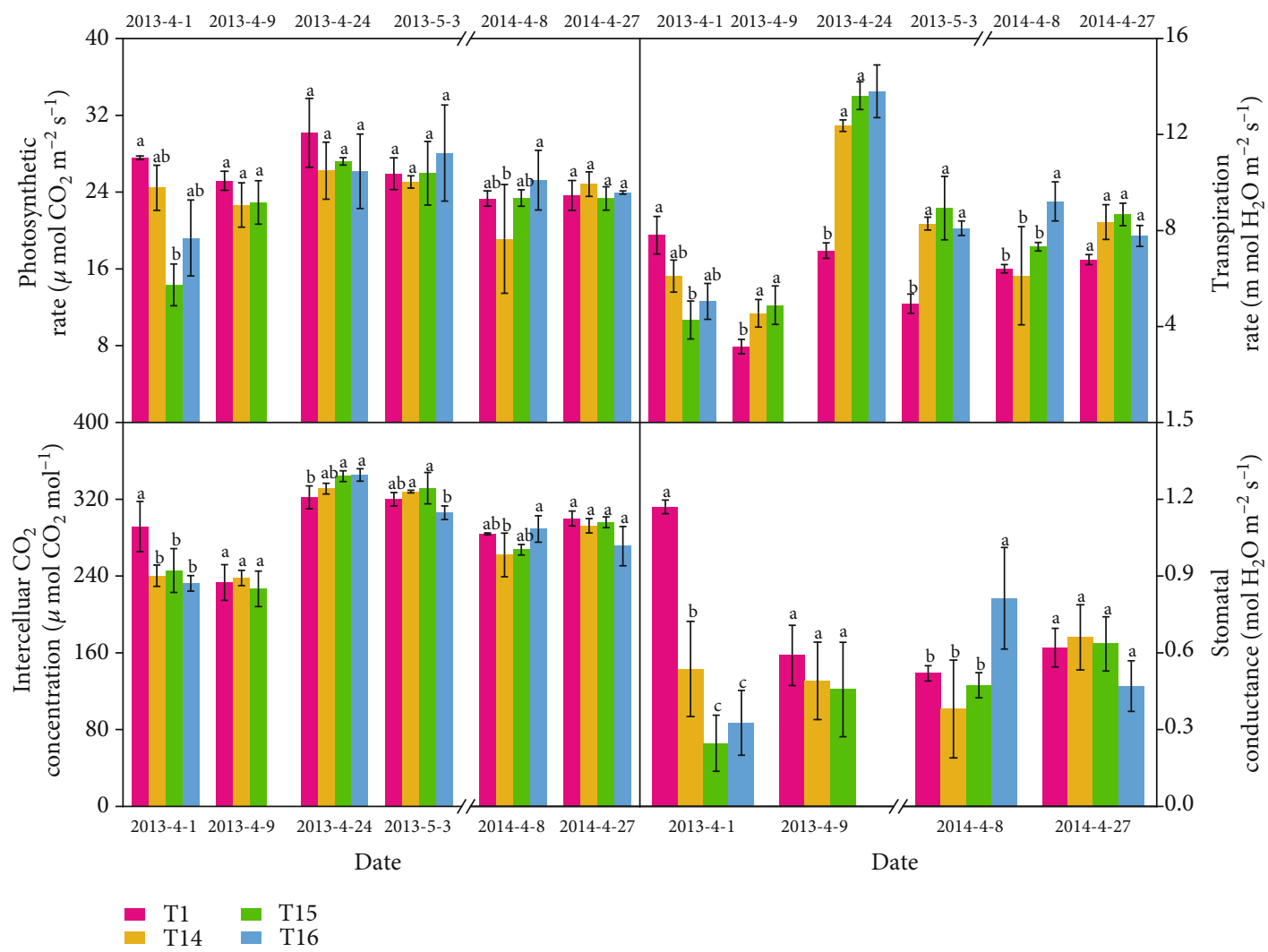

FIGURE 7: Variations in leaf gas exchange parameters of winter wheat under well-watered control treatment (T1), continuous moderate drought stress at seedling and jointing stages (T14), at jointing and heading stages (T15), and at heading and filling stages (T16), respectively. Data are the means \pm standard errors $(\mathrm{SE})$ of three replicates, where $n=3$ for the photosynthetic rate $(\mathrm{Pn})$, transpiration rate $(\mathrm{Tr})$, intercellular $\mathrm{CO}_{2}$ concentration (Ci), and stomatal conductance (Gs). Different letters above the bars indicate statistical significance $(p \leq 0.05)$. 


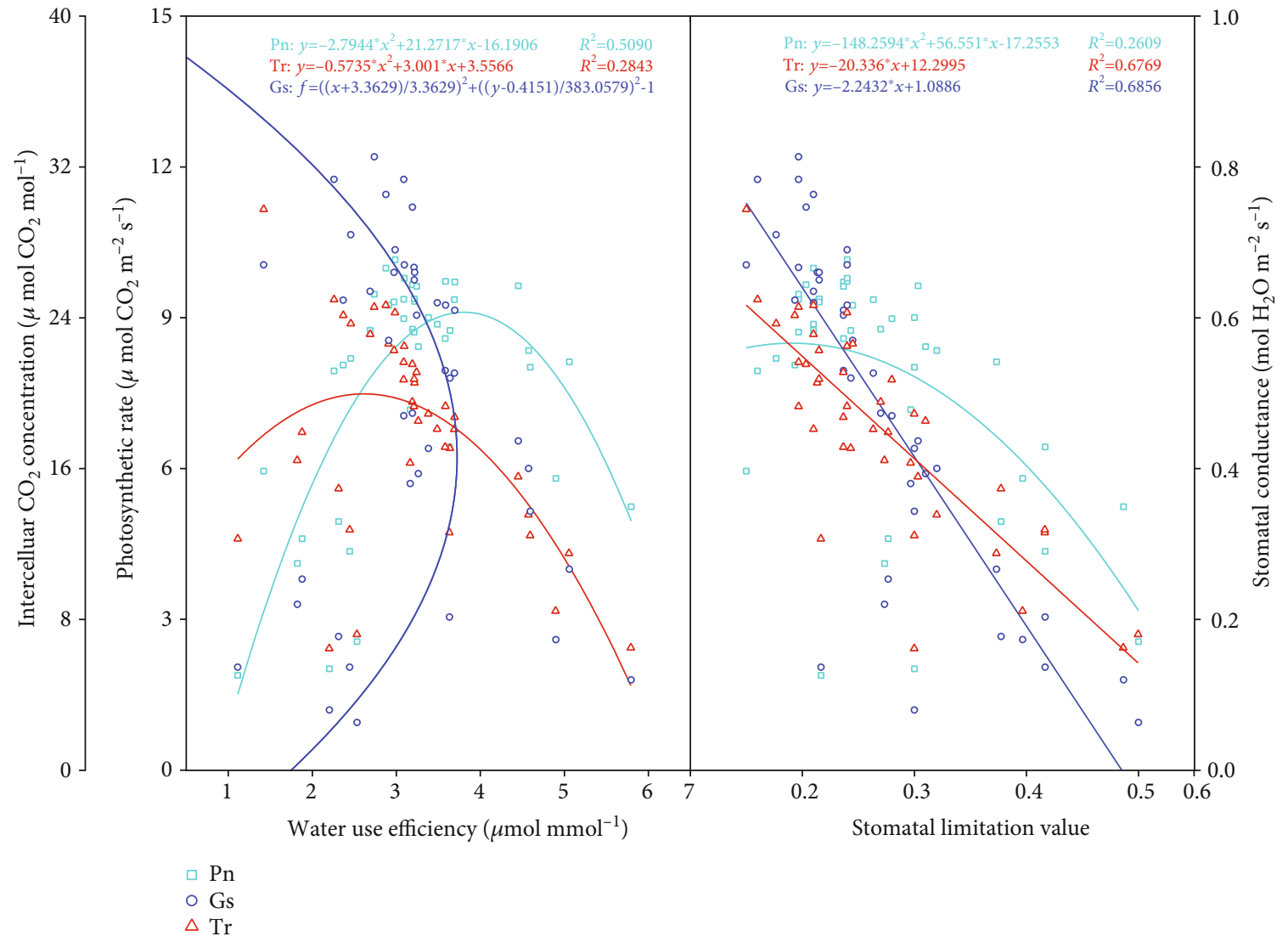

Figure 8: Relationships between leaf water use efficiency, stomatal limitation values, and gas exchange parameters of winter wheat.

adaptable to drought stress [37, 38]. When soil water is sufficient, stomatal conductance increases with the increase of photosynthetic active radiation intensity. Under severe drought, plants will suffer excessive water loss through transpiration, resulting in changes in leaf water potential and the decrease of the stomatal opening. However, under moderate water stress, the photosynthetic rate did not decrease or even became higher than that of nonstress treatment.

In this study, $\mathrm{WUE}_{1}$ decreased until nonstomatal restriction became a main limiting factor for leaf gas exchange, which was consistent with the previous studies [39, 40]. With the increase of $\mathrm{WUE}_{\mathrm{l}}, \mathrm{Pn}$ and Tr both increased first and then decreased. When $\mathrm{WUE}_{1}$ was about $2.62 \mu \mathrm{mol} \mathrm{mmol}^{-1}$, $\mathrm{Tr}$ reached the maximum value. When $\mathrm{WUE}_{1}$ reached $3.36 \mu \mathrm{mol} \mathrm{mmol}^{-1}$, the drought level increased from light to moderate water stress. Similarly, when $\mathrm{WUE}_{1}$ exceeded $3.81 \mu \mathrm{mol} \mathrm{mmol}^{-1}$, Pn reached the maximum value. It was when $\mathrm{WUE}_{1}$ reached $4.11 \mu \mathrm{mol} \mathrm{mmol}^{-1}$ that it began to decrease quickly, indicating that crops had suffered from severe water stress. At the same time, the nonstomatal factor had become a main limiting factor of leaf photosynthesis [41]. The recommendation of $\mathrm{WUE}_{1}$ threshold values (i.e., $W E_{1}$ of $2.62,3.36$, and $4.11 \mu \mathrm{mol} \mathrm{mmol}{ }^{-1}$ represents light, moderate, and severe drought levels, respectively) that define different levels of drought stress will be of more practical significance for realizing the unification of water-saving and high yield of wheat.
3.7. Crop Evapotranspiration, Grain Yield, and Water Use Efficiency. Crop evapotranspiration $\left(\mathrm{ET}_{\mathrm{c}}\right)$ was limited by drought at any growth stage (Table 1). Generally, $\mathrm{ET}_{c}$ decreased with the intensification of drought. Compared with light and moderate drought treatments, $\mathrm{ET}_{\mathrm{c}}$ of severe drought treatment at any growth stage was always the lowest. On average, grain yield and $\mathrm{ET}_{\mathrm{c}}$ of winter wheat in the 2012-2013 growing season were decreased by $7.38 \%$ and $6.63 \%$ (light drought), $10.3 \%$ and $7.94 \%$ (moderate drought), and $15.3 \%$ and $31.8 \%$ (severe drought), respectively, compared with CK. Similar results were also observed in 2013-2014. Grain yield of light and moderate drought treatments at the seedling stage generally decreased within $5 \%$, while water use efficiency (WUE) was generally higher, which indicated that moderate drought at the seedling stage was beneficial to improve WUE of winter wheat, and did not lead to significant yield reduction. Compared with $\mathrm{CK}$, WUE of drought treatments at heading and filling stages was decreased by up to $21.7 \%(2012-2013)$ and $27.5 \%(2013-2014)$, respectively. WUE was lowest under continuous drought conditions at middle growth stages. Under moderate water stress, the stomatal opening decreased significantly, and the transpiration rate decreased faster than the photosynthetic rate, giving rise to the highest WUE. Under severe water stress, the photosynthetic activity of mesophyll cells decreased, leading to stomatal limitation. 
TABLE 1: Crop evapotranspiration, grain yield, and water use efficiency of winter wheat under well-watered control conditions and light, moderate, and severe drought stress at different key growth stages during the 2012-2013 and 2013-2014 growing seasons.

\begin{tabular}{|c|c|c|c|c|c|c|}
\hline \multirow{2}{*}{ Treatments } & \multicolumn{2}{|c|}{ Grain yield $\left(\mathrm{kg} \mathrm{ha}^{-1}\right)$} & \multicolumn{2}{|c|}{ Crop evapotranspiration $(\mathrm{mm})$} & \multicolumn{2}{|c|}{ Water use efficiency $\left(\mathrm{kg} \mathrm{m}^{-3}\right)$} \\
\hline & $2012-2013$ & $2013-2014$ & $2012-2013$ & 2013-2014 & $2012-2013$ & $2013-2014$ \\
\hline $\mathrm{T} 1(\mathrm{CK})$ & $7545 a$ & $8023 a$ & $569.8 \mathrm{a}$ & $531.1 \mathrm{ab}$ & $1.33 \mathrm{abc}$ & $1.51 \mathrm{ab}$ \\
\hline $\mathrm{T} 2$ & $7318 \mathrm{a}$ & $7682 \mathrm{a}$ & $569.2 \mathrm{a}$ & $539.8 \mathrm{ab}$ & $1.29 \mathrm{bc}$ & $1.42 \mathrm{bc}$ \\
\hline $\mathrm{T} 3$ & $7318 \mathrm{a}$ & $7886 a$ & $541.7 \mathrm{ab}$ & $484.5 \mathrm{bc}$ & $1.36 \mathrm{abc}$ & $1.64 \mathrm{a}$ \\
\hline $\mathrm{T} 4$ & $7227 \mathrm{ab}$ & $5886 \mathrm{e}$ & 490.7bcde & $421.6 \mathrm{~d}$ & $1.48 \mathrm{ab}$ & $1.40 \mathrm{bcd}$ \\
\hline T5 & 7091ab & $7023 b$ & $513.8 \mathrm{abcd}$ & $510.8 \mathrm{ab}$ & $1.38 \mathrm{abc}$ & $1.38 \mathrm{bcde}$ \\
\hline T6 & $6818 \mathrm{abc}$ & $5864 \mathrm{e}$ & $526.6 \mathrm{abcd}$ & $526.6 \mathrm{ab}$ & $1.30 \mathrm{bc}$ & 1.11 fghi \\
\hline T7 & $6909 \mathrm{ab}$ & $5114 f$ & 470.1defg & $515.4 \mathrm{ab}$ & $1.48 \mathrm{ab}$ & $0.99 \mathrm{i}$ \\
\hline T8 & $6818 \mathrm{abc}$ & $6614 \mathrm{bcd}$ & $530.8 \mathrm{abc}$ & $559.7 \mathrm{a}$ & $1.28 \mathrm{bc}$ & 1.19efgh \\
\hline T9 & $6818 \mathrm{abc}$ & 6205 cde & $518 \mathrm{abcd}$ & $517.3 \mathrm{ab}$ & $1.32 \mathrm{abc}$ & $1.21 \mathrm{efgh}$ \\
\hline $\mathrm{T} 10$ & $6045 c d$ & $6227 \mathrm{cde}$ & $473.9 \mathrm{cdef}$ & $512.4 \mathrm{ab}$ & $1.28 \mathrm{bc}$ & $1.22 \mathrm{fefg}$ \\
\hline T11 & $6727 \mathrm{abc}$ & $6795 b c$ & $514.3 \mathrm{abcd}$ & $532.4 \mathrm{ab}$ & $1.30 \mathrm{bc}$ & $1.29 \mathrm{cdef}$ \\
\hline T12 & 6091cd & 6023de & $512.1 \mathrm{bcd}$ & $447.8 \mathrm{~cd}$ & $1.19 \mathrm{c}$ & $1.35 \mathrm{bcde}$ \\
\hline T13 & $5364 d$ & $4636 \mathrm{fg}$ & $415.8 \mathrm{~g}$ & $423.6 \mathrm{~d}$ & $1.29 \mathrm{bc}$ & 1.09ghi \\
\hline T14 & $6455 b c$ & $4614 \mathrm{fg}$ & $418.2 \mathrm{~g}$ & $452.3 \mathrm{~cd}$ & $1.54 \mathrm{a}$ & $1.02 \mathrm{hi}$ \\
\hline T15 & $5500 \mathrm{~d}$ & $4000 \mathrm{~g}$ & $426.6 f g$ & $493.9 b c$ & $1.29 \mathrm{bc}$ & $0.81 j$ \\
\hline T16 & $6455 b c$ & $6000 \mathrm{de}$ & 438.9efg & $491.7 \mathrm{bc}$ & $1.47 \mathrm{ab}$ & $1.22 \mathrm{defg}$ \\
\hline
\end{tabular}

Note: treatment means followed by the different letters are significantly different at $p \leq 0.05$.

\section{Conclusion}

Grain yield of light and moderate drought treatments at the seedling stage was similar to $\mathrm{CK}$, indicating that light and moderate water stress levels at the seedling stage did not generate an irreversible effect on wheat plants. However, severe drought in any growth stage caused significant negative effects on gas exchange parameters, $\mathrm{WUE}_{1}$, and grain yields of winter wheat. Based on the correlation between $\mathrm{WUE}_{1}$ and $\mathrm{Pn}$, $\mathrm{Tr}$, and Gs, the theoretical threshold values of $\mathrm{WUE}_{1}$ for light, moderate, and severe drought levels were 2.62, 3.36, and $4.11 \mu \mathrm{mol} \mathrm{mmol}^{-1}$, respectively. Photosynthetic rates of wheat leaves reached their maximum values when $\mathrm{WUE}_{1}$ was $3.81 \mu \mathrm{mol} \mathrm{mmol}^{-1}$. The $\mathrm{WUE}_{1}$ threshold values are useful to identify different levels of drought stress the crops suffered from and provide a theoretical reference threshold to achieve smart irrigation for winter wheat in the North China Plain.

\section{Data Availability}

The data used to support the findings of the study can be available upon request to the corresponding author.

\section{Conflicts of Interest}

All the authors declare no conflict of interest.

\section{Acknowledgments}

This study was financially supported by the Henan Water Conservancy Science and Technology Project (GG201509, GG201602), and Scientific and Technological Project of Henan Province (212102110069). The page fee for this manuscript comes from the project undertaken by the author.

\section{References}

[1] C. Su, S. Song, Y. Lu et al., "Potential effects of changes in climate and emissions on distribution and fate of perfluorooctane sulfonate in the Bohai Rim, China," Science of the Total Environment, vol. 613-614, pp. 352-360, 2018.

[2] D. Tilman, C. Balzer, J. Hill, and B. L. Befort, "Global food demand and the sustainable intensification of agriculture," Proceedings of the National Academy of Sciences of the United States of America, vol. 108, no. 50, pp. 20260-20264, 2011.

[3] Q. Fang, L. Ma, T. R. Green, Q. Yu, T. D. Wang, and L. R. Ahuja, "Water resources and water use efficiency in the North China Plain: current status and agronomic management options," Agricultural Water Management, vol. 97, no. 8, pp. 1102-1116, 2010.

[4] S. Sun, J. Liu, P. Wu, Y. Wang, X. Zhao, and X. Zhang, "Comprehensive evaluation of water use in agricultural production: a case study in Hetao Irrigation District, China," Journal of Cleaner Production, vol. 112, pp. 4569-4575, 2016.

[5] M. Giuliani, F. Carucci, E. Nardella et al., "Combined effects of deficit irrigation and strobilurin application on gas exchange, yield and water use efficiency in tomato (Solanum lycopersicum L.)," Scientia Horticulturae, vol. 233, pp. 149-158, 2018.

[6] T. Oda, K. Moriwaki, K. Tanigaki, Y. Nomura, and T. Sumi, "Irrigation ponds in the past, present, and future: a case study of the Higashi Harima Region, Hyogo Prefecture, Japan," Journal of Hydro-Environment Research, vol. 26, pp. 19-24, 2019.

[7] H. Kazem Attar, H. Noory, H. Ebrahimian, and A.-M. Liaghat, "Efficiency and productivity of irrigation water based on water balance considering quality of return flows," Agricultural Water Management, vol. 231, p. 106025, 2020.

[8] S. M. Ismail and K. Ozawa, "Improvement of crop yield, soil moisture distribution and water use efficiency in sandy soils by clay application," Applied Clay Science, vol. 37, no. 1-2, pp. 81-89, 2007. 
[9] T. Améglio, P. Archer, M. Cohen et al., "Significance and limits in the use of predawn leaf water potential for tree irrigation," Plant and Soil, vol. 207, no. 2, pp. 155-167, 1998.

[10] A. Qin, D. Ning, Z. Liu et al., "Structural equation modeling of soil moisture effects on evapotranspiration of maize in the North China Plain," National Academy Science Letters, vol. 43, no. 3, pp. 219-224, 2020.

[11] J. Zou, Z. Xie, C. Zhan et al., "Effects of anthropogenic groundwater exploitation on land surface processes: a case study of the Haihe River Basin, northern China," Journal of Hydrology, vol. 524, pp. 625-641, 2015.

[12] D. Feng, J. Zhang, C. Cao et al., "Soil salt accumulation and crop yield under long-term irrigation with saline water," Journal of Irrigation and Drainage Engineering, vol. 141, no. 12, pp. 04015025-04015729, 2015.

[13] G. D. Salvucci, "Estimating the moisture dependence of root zone water loss using conditionally averaged precipitation," Water Resources Research, vol. 37, no. 5, pp. 1357-1365, 2001.

[14] A. Porporato, F. Laio, L. Ridolfi, and I. Rodriguez-Iturbe, "Plants in water-controlled ecosystems: active role in hydrologic processes and response to water stress: III. Vegetation water stress," Advances in Water Resources, vol. 24, no. 7, pp. 725-744, 2001.

[15] G. R. Miller, D. D. Baldocchi, B. E. Law, and T. Meyers, “An analysis of soil moisture dynamics using multi-year data from a network of micrometeorological observation sites," Advances in Water Resources, vol. 30, no. 5, pp. 1065-1081, 2007.

[16] C. Jiabing, X. Di, S. Nan, and W. E. I. Zheng, "Real-time monitoring system of crop canopy temperature and soil moisture for irrigation decision-making," Transactions of the Chinese Society for Agricultural Machinery, vol. 46, no. 12, pp. 133139, 2015.

[17] M. Han, H. Zhang, J. L. Chávez, L. Ma, T. J. Trout, and K. C. DeJonge, "Improved soil water deficit estimation through the integration of canopy temperature measurements into a soil water balance model," Irrigation Science, vol. 36, no. 3, pp. 187-201, 2018.

[18] M. Culman, C. M. de Farias, C. Bayona, and J. D. Cabrera Cruz, "Using agrometeorological data to assist irrigation management in oil palm crops: a decision support method and results from crop model simulation," Agricultural Water Management, vol. 213, pp. 1047-1062, 2019.

[19] Y. Zhang, E. Kendy, Y. Qiang, L. Changming, S. Yanjun, and S. Hongyong, "Effect of soil water deficit on evapotranspiration, crop yield, and water use efficiency in the North China Plain," Agricultural Water Management, vol. 64, no. 2, pp. 107-122, 2004.

[20] S. Hao, H. Cao, H. Wang, and X. Pan, "The physiological responses of tomato to water stress and re-water in different growth periods," Scientia Horticulturae, vol. 249, no. 1, pp. 143-154, 2019.

[21] X. Fang, Y. Li, J. Nie et al., "Effects of nitrogen fertilizer and planting density on the leaf photosynthetic characteristics, agronomic traits and grain yield in common buckwheat (Fagopyrum esculentum M.)," Field Crops Research, vol. 219, no. 4, pp. 160-168, 2018.

[22] A. Saryoko, Y. Fukuda, I. Lubis, K. Homma, and T. Shiraiwa, "Physiological activity and biomass production in crop canopy under a tropical environment in soybean cultivars with temperate and tropical origins," Field Crops Research, vol. 216, no. 12 , pp. $209-216,2018$.
[23] A. B. Heinemann, L. F. Stone, and N. K. Fageria, "Transpiration rate response to water deficit during vegetative and reproductive phases of upland rice cultivars," Scientia Agricola, vol. 68, no. 1, pp. 24-30, 2011.

[24] T. Zenone, M. Fischer, N. Arriga et al., "Biophysical drivers of the carbon dioxide, water vapor, and energy exchanges of a short-rotation poplar coppice," Agricultural and Forest Meteorology, vol. 209-210, pp. 22-35, 2015.

[25] G. Shao, J. Cui, S. Yu et al., "Impacts of controlled irrigation and drainage on the yield and physiological attributes of rice," Agricultural Water Management, vol. 149, pp. 156-165, 2015.

[26] X. Li, S. Kang, X. Zhang, F. Li, and H. Lu, "Deficit irrigation provokes more pronounced responses of maize photosynthesis and water productivity to elevated $\mathrm{CO}_{2}$," Agricultural Water Management, vol. 195, pp. 71-83, 2018.

[27] R. A. C. Mitchell, V. J. Mitchell, and D. W. Lawlor, "Response of wheat canopy $\mathrm{CO}_{2}$ and water gas-exchange to soil water content under ambient and elevated $\mathrm{CO}_{2}$," Global Change Biology, vol. 7, no. 5, pp. 599-611, 2001.

[28] L. Zheng, J. Ma, X. Sun et al., "Responses of photosynthesis, dry mass and carbon isotope discrimination in winter wheat to different irrigation depths," Photosynthetica, vol. 56, no. 4, pp. 1437-1446, 2018.

[29] S. Zhang, Q. Li, K. Ma, and L. Chen, "Temperature-dependent gas exchange and stomatal/non-stomatal limitation to $\mathrm{CO}_{2}$ assimilation of Quercus liaotungensis under midday high irradiance," Photosynthetica, vol. 39, no. 3, pp. 383-388, 2001.

[30] J. Lampurlanés, D. Plaza-Bonilla, J. Álvaro-Fuentes, and C. Cantero-Martínez, "Long-term analysis of soil water conservation and crop yield under different tillage systems in Mediterranean rainfed conditions," Field Crops Research, vol. 189, pp. 59-67, 2016.

[31] A. Qin, Y. Fang, D. Ning et al., "Incorporation of manure into ridge and furrow planting system boosts yields of maize by optimizing soil moisture and improving photosynthesis," Agronomy, vol. 9, no. 12, p. 865, 2019.

[32] H. Ozaki, R. Oguchi, and K. Hikosaka, "Dependence of functional traits related to growth rates and their $\mathrm{CO}_{2}$ response on multiple habitat climate factors across Arabidopsis thaliana populations," Journal of Plant Research, vol. 131, no. 6, pp. 987-999, 2018.

[33] Y. Qu, P. Song, Y. Hu et al., "Regulation of stomatal movement by cortical microtubule organization in response to darkness and ABA signaling in Arabidopsis," Plant Growth Regulation, vol. 84, no. 3, pp. 467-479, 2018.

[34] A. Sallam, A. M. I. Mourad, W. Hussain, and P. Stephen Baenziger, "Genetic variation in drought tolerance at seedling stage and grain yield in low rainfall environments in wheat (Triticum aestivum L.)," Euphytica, vol. 214, no. 9, 2018.

[35] J. Niu, S. Zhang, S. Liu et al., "The compensation effects of physiology and yield in cotton after drought stress," Journal of Plant Physiology, vol. 224-225, pp. 30-48, 2018.

[36] L. Liu, W. Hao, Q. Bai, X. R. Mei, and Y. L. Yan, "Differential compensatory effects of winter wheat in water stress and rewatering during jointing stage in North China," Journal of Irrigation and Drainage, vol. 30, no. 2, pp. 37-40, 2011.

[37] E. Lefi, H. Medrano, and J. Cifre, "Water uptake dynamics, photosynthesis and water use efficiency in field-grown Medicago arborea and Medicago citrina under prolonged Mediterranean drought conditions," Annals of Applied Biology, vol. 144, no. 3, pp. 299-307, 2004. 
[38] X. Cheng, F. Zhang, and S. Chai, "Stomatal response of spring wheat and related affecting factors under different irrigation treatments," Chinese Journal of Applied Ecology, vol. 21, no. 1, pp. 36-40, 2010.

[39] J. R. Ehleringer and C. S. Cook, "Carbon and oxygen isotope ratios of ecosystem respiration along an Oregon conifer transect: preliminary observations based on small-flask sampling," Tree Physiology, vol. 18, no. 8-9, pp. 513-519, 1998.

[40] M. E. Salvucci and S. J. Crafts-Brandner, "Inhibition of photosynthesis by heat stress: the activation state of Rubisco as a limiting factor in photosynthesis," Physiologia Plantarum, vol. 120, no. 2, pp. 179-186, 2004.

[41] R. B. Thompson, M. Gallardo, L. C. Valdez, and M. D. Fernández, "Using plant water status to define threshold values for irrigation management of vegetable crops using soil moisture sensors," Agricultural Water Management, vol. 88, no. 1-3, pp. 147-158, 2007. 